\title{
Current Status of Environmental Protection Measures in China
}

\author{
Chao Liu, Shenggao Cheng \& Kefeng Zeng \\ China University of Geosciences, Wuhan 430074, China
}

\begin{abstract}
Human activities affect the environment more or less negatively due to thriving engineering constructions such as resources exploitation, municipal projects and so on. It is encouraging that, by applying some environmental protection measures to decrease pollution in cities and prevent disturbance from geo-environment due to constructions, have made big progress for the present. However, it is far from our utmost expect of environment protection. The inherent complexity and varied nature of geo-environment challenge policy makers how to assess the active effectiveness of environmental protection in scientific approaches., This paper, starting from antecedents achievements in China, outlined the present situation of environment protection in China, and featured the types and purposes of 21st century environmental sures in terms of their natures and functions, thereby comprehensively proposed research respective. Research conclusions were included: 1) the awareness to environmental protection measures is increasing and it present higher growth rate in 2006 and 2007 in terms of analyzing publications focused on environment protection; 2) "passive" environmental protection measures account for most of human activities, while less attentions were paid to the precaution for the source; 3) Awareness to the economic applicability and efficiency of environmental protection measures
\end{abstract}

Keywords: $21^{\text {st }}$ century, Environmental protection, Measure, Progress trend

\section{Introduction}

Environmental protection is now a major focus for the whole world. These years, Chinese government and Chinese people have invested great workforce and material resources in environmental protection, consuming a lot of time and money. The environmental protection measures in China start from construction of environmental protection facilities. Back in 1972, the State Council demanded that construction of factories should be accompanied by the project of utilizing three wastes via simultaneously designing, constructing and putting into construction(called "three-simultaneous"), in approving and transferring "The Report by State Planning Commission and National Construction Committee about the pollution in Kwanting Reservoir and its solution". From then on, there are varies of regulations, laws and other forms of interference such as the management system of simultaneously designing, constructing and putting into production, "Law of Environmental Protection of the People's Republic of China" and economic, media, education and so on. With varies forms, there is only one purpose, that is to protect the environment in different methods.

This paper made searches based on documents cited by China National Knowledge Infrastructure (CNKI) full-text databases from 2000.1 to 2007.12. The time of search was a.m. on December 31st, 2007, with "environmental protection measures "and" environmental protection +measure" as key words for "superscription" and performed accurate matching in selected database, which is China Journal full-text database. Two searches resulted in total 322 documents, and after weeding out classified documents, which can not be downloaded and read, and the overlaps, there are 227 documents left. After printing, checking and counting page by page for environmental protection measures, it was found out that 23 documents do not contain specific environmental protection measures, for they are just news reports or simple slogans of environmental protection. So the actual samples involved in the statistics are 204 .

\section{Statistical Methods and Statistics}

\subsection{Document Statistics}

204 samples are given a digital cod according to the year: year 2000, 1-20; year 2001, 21-36; year 2002 37-56; year 2003, 57-81; year 2004, 82-105; year 2005, 106-128; year 2006, 129-165; year 2007, 166-204. For example, code 20 represent that the measure appears in the $20^{\text {th }}$ document.

According to the statistical Fig.1 of the number of documents in different year, the general trend is growth, indicating that there is more and more attention to the environmental protection measures. In statistics, there are the highest document numbers in 2006 and 2007, indicating the most attention in these two years. 


\subsection{Environmental protection measures Statistics}

This paper drew statistics according to each and every specific method, measure or management advice in 204 sample documents and each method is counted as one environmental protection measure(normally there are various such measures in one document).And the environmental protection measures are classified according to their nature into regulation, policy and law measures, technique reform measures, planning layout and regional management measures, and educational, propaganda and awareness measures. The environmental protection measures with higher appearing rate are as follows, and the others is as data source in classified statistics analysis, which does not be talked about in this thesis.

I) Regulation, policy and law measures

Based on environmental management system of China, it can be classified into environmental management system such as environmental law and "three-simultaneous" system, contamination draining fee system, environmental impact assessment system, and industry policy and economic policy and so on. Specific measures which appear more than 10 times are:(1) pollutant standard emission and total emission control(ZHU D-M, 2000, pp.3-5; SHAO F. , 2000, pp.39-41; WU X-F., 2005, pp.72-76; HAO M-J, ZHAO Y-Q, ZHANG L-J, et al., 2006, ), 31 times;(2)to improve environmental protection laws and regulations, complete standard emission system, manage environment according to laws and standard(ZHAO X-M., 2004, pp.5; YU X-F, LI M-F., 2006, pp.54-55; Ge C-Z, GAO S-T, et al., 2007, pp.23-25), 30 times;(3) environmental impact review system(ZHANG H-Y., 2005, pp.7-8; LIU Y-L., 2007, pp.40-42), 28 times; (4)to readjust industry and product structure by using economic and industry policy, wash out enterprises and projects with heavy pollution and low efficiency on energy and resource utilization by force(ZHU D-M, 2000, pp.3-5;MAO N-H, LIU B, CHEN X-G.., 2003, pp.58-59), 27 times; (5) environmental protection "three-simultaneous" system(PENG H, PENG X., 2002, pp.23), 20 times;(6)implement environmental protection goal responsibility system, and thus environmental protection is an important part in assessing cadres' achievement, 17 times;(7) pollutant draining fee and environmental tax system(WANG N, LIU J-S., 2000, pp.12-14), 16 times;(8) ecological environment compensation system(GENG Y.,2006, pp.62-65) 10 times.

\section{II) Technique reform measures}

This kind of measures optimize and alter resource utilization means, decrease generation of pollutants and dispose pollution and ecological damage through engineering technique reform. This includes not only various engineering technique reform in different departments and production links such as in mining, road construction, bridging, building, industry and agriculture production and so on, but also the technique reform in waste utilization process. Specific measures which appear more than 10 times are:(1)restoration and treatment of damaged land(HUANG R-Y., 2007, pp.73), 55 times; (2)waste recycling method reform(HUANG B-T,WEI T., 2004, pp.105-109), 50 times; (3)groundsill and slope protection(ZHENG G-H., 2001, pp.46; WANG L, WANG B-J., 2004, pp.8-9; WANG X, XING H-T., 2004, pp45-46; CHEN H-D, LIU X-B, YU L., 2007, pp.16-18), 45 times;(4) noise prevention measures(HUANG R-Y.2007, pp.73-75), 38 times-among which 30 articles referred putting shield, sound insulation woods, acoustic barrier, vibration reduction slot and other ways to reduce noise pollution, and 15 articles mentioned mechanical maintenance to remain the lowest acoustic level;(5)applying advanced production facilities, environmental protection equipments, and techniques to decrease emission of pollutants, 25 times;(6)to select new raw materials to get cleaner material and environmental protection products, 16 times;(7)to optimize the time for construction(YU X-G, LI C-H, SUN C-S, et al., 2005, pp.226-227), 15 times;(8)to use advanced monitoring and control equipment and information processing technology,15 times;(9)to update and optimize the dust removal equipment system, 15 times;(10)to optimize the environmental protection design of project construction, instrument and equipment(LIU Y-L., 2007, pp.40-42), 13 times-among which 9 articles mentioned providing passing channels for wild animals;(11)to optimize construction or exploitation methods(ZENG J-X., 2006, pp.66-67), 13 times;(12)to utilize new technologies to increase resource utilization efficiency and decrease energy consumption and pollutant emission, 12 times;(13)to alter the system obturation, 11 times;(14)to ascertain industry type and scale according to environment carrying capacity, 10 times.

III) Planning, layout and regional management measures

This kind of measures include establishment and management of nature reserve, ecology protection planning, urban function partition, construction of regional infrastructure, resource protection, mine management and so on. Specific measures which appear more than 10 times are:(1) construction organization and management, 56 times-among which 18 theses mentioned reasonable layout of construction encampment, soil excavating and depositing site, and strictly control of temporary land use scale, and 15 theses mentioned environmental project supervision and inspection of environmental protection bureau;(2)vegetation planting and greening management of slope, factory zone, mine zone, community, river source and other areas(YANG J-B.,2007,pp.14-16), 53 times;(3)reasonable planning, scientific siting and route selection concerning landform and surface features(LIU Y-L.(2007, pp.40-42), 38 times;(4) cleaning and classified management of domestic sewage and garbage, 36 times;(5)planning of environmental protection and sight construction(ZHAO X-M.,2004, pp.43), 28 times;(6)perfection of environment management and supervision institution 
and environmental management system(YANG J-B.,2007,pp.14-16); 27 times;(7)disposal of project construction waste water, road surface water, waster water of vehicle mechanical maintenance cleaning, 23 times;(8)traffic, transport and road management, 19 times;(9)perfection of national environment monitor network and environment information system, and precaution of disaster and monitor of regional resource and environment, 19 times;(10)establishment of nature reserve in places such as swamp, forest, river source, geological relics and other places(YANG J-B.,2007, pp.14-16), 14 times;(11)project management by bringing environmental protection activities into contracts, 13 times;(12)reasonable layout of enterprises and factory area, 12 times;(13)management of agriculture and livestock husbandry production, 11 times;(14)making resource utilization plans to use resource reasonably(YANG J-B.,2007, pp.14-16), 10 times;(15)equipment check and maintenance, 10 times;(16) construction of environmental protection infrastructure, 10 times.

IV) Education, propaganda and awareness measures

This kind of measures concerns with education and propaganda, in order to promote environmental protection consciousness of the entire people. Specific measures that appear more than 10 times are: (1) environmental protection common sense and ideological education, and technical measures training(YANG J-B.,2007,pp.14-16), 24 times; (2) ubiquity of environmental protection knowledge, and mobilization of public for environmental protection campaign, 23 times. Other theses concerned with measures such as improving decision making of project planning and environmental protection consciousness of prospective designer; strengthening propaganda of hygiene and disease control and security training; consciousness of energy saving and consumption reduction propaganda and education; promoting greener consumption and harmonious development and so on.

\section{Analysis and Classification}

\subsection{Classification Statistics Chart}

This paper makes statistics on all kinds of data in two methods separately. Both methods make statistics according to different year and then perform contrast to make sure the total number of environmental protection measures is consistent in each year so as to assure the veracity of the statistics.

Based on environmental protection measures (as data source) in 204 sample documents, we classify them according to the method mentioned in section 2.2 into regulation, policy and law measures (type I: the statistics are 23, 25, 10, 22, 22, $31,59,69$, from 2000 to 2007), technique reform measures (type II: the statistics are 16, 14, 19, 46, 55, 34, 91, 81, from 2000 to 2007), planning layout and regional management measures (type III: the statistics are 20, 24, 21, 66, 79, 96, 125, 142, from 2000 to 2007), and educational, propaganda and awareness measures (type IV: the statistics are 3, 12, 6, 9, 9, 9, 15, 15, from 2000 to 2007), and drew the statistics about the number of environmental protection measures as shown in Fig.2. According to the function of environmental protection measures we can divide them into front-prevention measure (type a: the statistics are 13, 18, 18, 35, 39, 47, 72, and 80, from 2000 to 2007), end treatment measure (type b: the statistics are $10,11,12,33,43,38,68$, and 67 , from 2000 to 2007), process optimization measure (type c: the statistics are 14, 10, 9, 24, 39, 23, 49, and 58, from 2000 to 2007) and comprehensive measure (type d: the statistics are 23, 36, 17, 51, 44, 61, 102, and 108, from 2000 to 2007), and the statistics are shown in Fig.3. Both statistics show that the total number of environmental protection measures in each year is consistent. In these 8 years-from 2000 to 2007-the statistics are $62,75,56,143,165,170,290,313$ separately, indicating that the statistical definition and the count of these recorded environmental protection measures are the same and accurate.

\subsection{Statistical Analysis}

(1) analysis of total environmental protection measure number: from 2000 to 2002 the total number remain stable with $62,75,56$ respectively; in 2003 there is a clear increase in total number which reached 143; during year 2004 and 2005 there are slow increase; in 2006 and 2007 the increase rate soared and break through 300 in 2007.

(2)classified data analysis: during 8 years the curve of type IV goes mild for about 10 times each year; from 2000 to 2002 type III remained stable, while from 2003 the number started increasing; generally speaking type II has been increasing while in 2002 and 2005 there were lower points; type I shows a stable increase in 8 years. If we just consider the number, type $\mathrm{a}$ and $\mathrm{d}$ shows apparent increase every year, while type $\mathrm{b}$ and $\mathrm{c}$ rises and falls.

(3) Combining two classification method, the statistics are as Tab. 1. Id, IIb, IIIa and IIId show higher rate, followed by IIc, IIIc and IIIb.

\section{Conclusion and Discussion}

The following conclusion can be drawn via data analysis:

(1) During 2000 and 2007, Chinese academic periodicals' attention to environmental protection problems are increasing, and the increase can be divided into three phases. From 2000 to 2002, it is stable phase with 16-20 theses and 56-75 environmental protection measures a year. From 2003 to 2005, it is the increase phase with 23-25 theses and 143-170 environmental protection measures a year. From 2006 to 2007, it is soaring phase with 37 and 39 theses and 290 and 
313 environmental protection measures each year.

(2) Most measures are planning, layout and regional management measures (III), with apparent increase. This indicates that in recent years scholars were more concerned with researching the effect of planning, layout and regional management on environmental protection. The least measures are education, propaganda and awareness measures (IV), which indicates that the attention to these aspects is inadequate.

(3) There is a lot of type Id environmental protection measures with apparent increase, which indicates that there are more and more broad attention to environmental laws, regulations, policies and systems which are comprehensive and concerning overall process. There are also a lot of type IIb measures with apparent increase, indicating there are more attention to technique reform measures while these measures are still end treatment measures. There are many type IIIa and IIId measures with increase, indicating the effect of planning, layout and regional management measures on environmental protection are mainly shown in front-prevention and comprehensive management measures.

Problems deserving further discussions are:

(1) It may due to national policy that in 2003 and 2006 there were great increase in the number of environmental measures, especially the attention from the entire people brought by "environmental protection storm". However, "passive" measures played a major part in that it is policy-oriented and mainly rule of man with inadequate prevention measures. There should be more thoughts and research on the structure of measures, the methods of protection and on more effective way to protect the environment.

(2) It is worthwhile to discuss which measures are low cost, highly efficient and suitable to the development of our society and how to frugally protect the environment.

\section{References}

Chen H-D, Liu X-B, Yu L. (2007). Ecological Environment Protective Measures in the Qinghai-Tibet Highway Rebuilding Project. Environment and Sustainable Development, 2007(3):16-18.

Ge C-Z, Gao S-T, et al. (2007). the Safeguard of State Environmental Protection in the Eleventh Five-Year. Environment Protection, 2007(23):23-25.

Geng Y. (2006). Suggest to strengthen entironmental protection of Tibet plateau. Qinghai Social Sciences, 2006(3):62-65.

Hao M-J, Zhao Y-Q, Zhang L-J, et al. (2006). Environmental Protection Measure and Countermeasure During the Eleventh Five-Year in Shenyang. Sciences of Environmental Protection, 2006(3): 52-54.

Huang B-T, Wei T. (2004). Intraduction of High-grade Highway Environmental Protection Measures. Technology of Highway and Transport, 2004(4): 105-109.

Huang R-Y. (2007). Environmental Protection in the Water Conservancy and Hydroelectricity Project Building Site. Pearl River, 2007(2):73-75.

Liu Y-L. (2007). Environmental Protection Measures in the Process of Hydropower Plant Construction. Environmental Science Survey, 2007, 26(3):40-42.

Mao N-H, Liu B, Chen X-G.. (2003), EU Organic Livestock production with Kindness to Environment. Environmental Protection, 2003(12): 58-59.

Peng H, Peng X. (2002). The establishment and monitoring of entironmental protection measure in Non-Pollution EIA. North Environment, 2002(2): 23.

Qin M-Z. (2001). Biological Environment Measures of United States Land Uses: BufferStrips. Journal of Soil and Water Conservation, 2001, 15(1): 119-121.

Shao F. (2000). The measure of environmental protection and renovation for Wusong industrial park. Territory \& Natural Resources Study, 2000(1):39-41.

Tian X-Z. (2007). On measures for Eco-environment Protection in USA. Ecological Economy, 2007(2):315-316.

Wang L, Wang B-J. (2004). The measure of forest environment protection in ST.Paul Brazil. Scientific and Technical Information of Soil and Water Conservation, 2004(4): 8-9.

Wang N, Liu J-S. (2000). The pollution and environmental protection of villages and towns enterprise. North Environment, 2000(4): 12-14.

Wang P-Q. (2002). The question and countermeasure of environmental protection in China. Journal of Inner Mongolia Radio \& TV University, 2002(1): 71.

Wang X, Xing H-T. (2004). Ecological Environmental protection countermeasure for Real Estate Project. Urban Environment \& Urban Ecology, 2004(4):45-46. 
Wu X-J, Zu T-X. (2001). The research summarization of entironmental protection measure in west of China these years. Gansu Social Sciences, 2001(2): 17-22.

$\mathrm{Wu}$ X-F. (2005). Legal rules, polices and measures on marine environmental protection of China. Marine Environmental Science, 2005(3): 72-76.

Yang J-B. (2007). Discussion Protection Measures for eco-environemnt to Ebinur Lake Watershed. Water Resources and Hydropower Engineering, 2007(10):14-16.

Yu X-G, Li C-H, Sun C-S, et al. (2005). Study on Protection Measures for Eco-environment of Wetlands in Jilin. Research of Soil and Water Conservation, 2005(6): 226-227.

Yu X-F, Li M-F. (2006). Sustainable Development and Environmental Protection Measures of Shimen Coal Fired Power Plant. Electric Power Environmental Protection, 2006(4):54-55.

Zeng J-X. (2006). Environmental Protection Measures During Expressway Construction. Technology \& Economy in Areas of Communications, 2006(3):66-67.

Zhang H-Y. (2005). The Study on Highway Environmental Protection and Measures. SHanxi Science \& Technology of Communications, 2005(6):7-8.

Zhao X-M. (2004). Measures of Agriculture Environment Protection. Gansu Agriculture, 2004(12):39.

Zheng G-H. (2001). The government measure of environment protection in Norway. Environmental Protection, 2001(6): 46.

Zhu D-M. (2000). The impact of WTO to environmental protection and foreign trade in China. Environment Herald, 2000(2): 5-8.

Table 1. Environmental protection measures classification statistics of respective year

\begin{tabular}{|c|c|c|c|c|c|c|c|c|c|}
\hline & sort & 2000 & 2001 & 2002 & 2003 & 2004 & 2005 & 2006 & 2007 \\
\hline \multirow{4}{*}{ I } & Ia & 4 & 3 & 5 & 1 & 0 & 7 & 11 & 11 \\
\hline & $\mathrm{Ib}$ & 0 & 1 & 0 & 0 & 1 & 0 & 0 & 3 \\
\hline & Ic & 6 & 4 & 1 & 1 & 4 & 2 & 9 & 6 \\
\hline & Id & 13 & 17 & 4 & 20 & 17 & 21 & 39 & 49 \\
\hline \multirow{4}{*}{ II } & IIa & 2 & 2 & 2 & 5 & 5 & 2 & 9 & 11 \\
\hline & IIb & 8 & 9 & 10 & 25 & 31 & 21 & 52 & 43 \\
\hline & IIc & 5 & 2 & 6 & 13 & 15 & 6 & 21 & 29 \\
\hline & IId & 1 & 1 & 1 & 3 & 4 & 5 & 9 & 4 \\
\hline \multirow{4}{*}{ III } & IIIa & 8 & 5 & 7 & 25 & 32 & 33 & 42 & 51 \\
\hline & IIIb & 2 & 1 & 2 & 8 & 11 & 17 & 16 & 21 \\
\hline & IIIc & 3 & 3 & 1 & 10 & 19 & 14 & 19 & 23 \\
\hline & IIId & 7 & 15 & 12 & 23 & 17 & 32 & 49 & 47 \\
\hline \multirow{4}{*}{ IV } & IVa & 1 & 8 & 4 & 4 & 2 & 5 & 10 & 7 \\
\hline & $\mathrm{IVb}$ & 0 & 0 & 0 & 0 & 0 & 0 & 0 & 0 \\
\hline & IVc & 0 & 1 & 1 & 0 & 1 & 1 & 0 & 0 \\
\hline & $\mathrm{IVd}$ & 2 & 3 & 1 & 5 & 6 & 3 & 5 & 8 \\
\hline
\end{tabular}



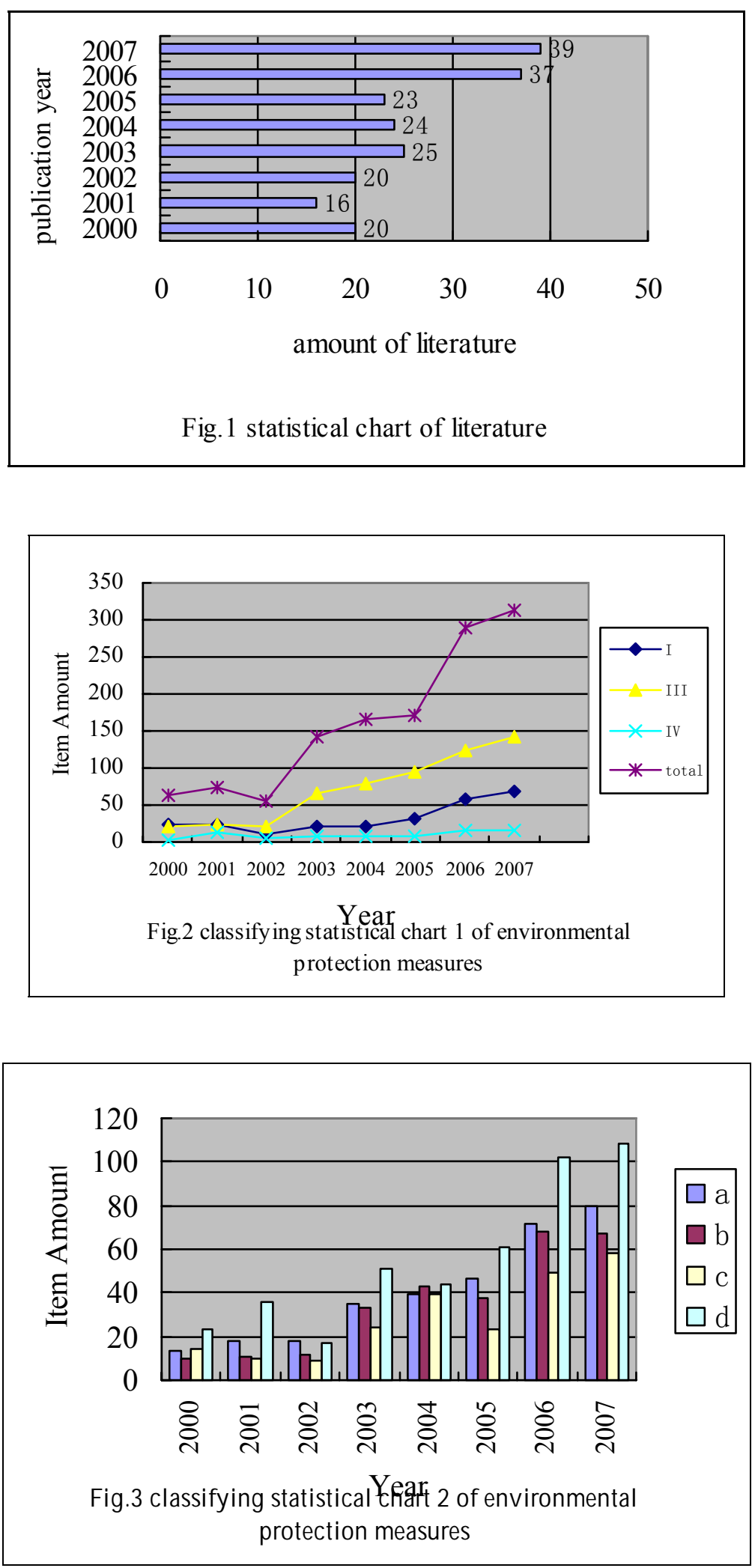